\title{
Optimization of B-Glucan Production from Lower Fungi using Central Composite Design and its Biological Application
}

\author{
Balaji Paulraj* \\ Department of Biotechnology, \\ MGR College, Hosur - 635109
}

\author{
T. Saravanan \\ Department of Microbiology \\ Vysya College, Salem-636 103
}

\begin{abstract}
Production of $\beta$-glucan is mainly used for cancer therapy. The most well-known are those occur in fungal grains such as cereal and other micro-organisms. The most important beta glucan from a nutritional and ingredient standpoint is that derived from fungal grain. Optimization of medium ingredients for the production of mycelial $\beta$-glucan from lower fungi in submerged fermentation and antioxidant activity of $\beta$-glucan was carried out.
\end{abstract}

Keywords

$\beta$-glucan, CCD, RSM, FTIR, Antioxidant activity

\section{INTRODUCTION}

The worldwide food industry uses 70,000 tonnes of polysaccharides per year as thickening agents, stabilizers and texturisers. As the emerging food products become more complex and diverse, the requirement for new and versatile additives is stronger. $\beta$-Glucans are a group of glucose polymers that form a fibrous structural extracellular matrix with in the cell walls of yeast [1] plants [2,3] and some micro organisms [4]. Fungi are currently of interest because they are a biologically rich source of various active substances. Polysaccharides have emerged as an important class of bioactive substances. Most of the polysaccharides mediating biological activities from mycelia were endopolysaccharides or exopolysaccharides [5]. Over the past 20 years there has been increasing interest in the large-scale production of fungal polysaccharides by submerged fermentation, notably in view of their diverse pharmacological activities [6,7]. Various $\beta$ glucans have been studied, and many exhibit bioactivities and confer health benefits $[8,9]$. With a view to develop $\beta$-glucancontaining value-added products, exploration of new sources of $\beta$-glucans and characterization of their origin-dependent bioactivities are of importance. Among the $\beta$-glucans of fungal polysaccharides, comprising intracellular-, structural-, and exocellular-polysaccharide, fungal exopolysaccharide are most favored by manufacturers, mainly due to its ease of recovery. However, up to now, no detailed investigations have been conducted on composition characterization and anti oxidative capacities of different $\beta$-glucan isolated from Aspergillus species. An overview of the literature on the production, characterization and medicinal properties of the fungal polysaccharides indicates that there are gaps in knowledge which remain to be explored and there is a lot of scope for isolating new polysaccharides from lower fungi with significant bioactivity. Keeping this perspective, the present investigation was designed to survey and screen media for $\beta$ glucan production and their biological activity.

\section{MATERIALS AND METHODS}

\subsection{Preparation of $\beta$-glucan}

The crude Beta-glucan was prepared according to the reported method with some modifications [10]. Briefly, the mycelia of lower fungi were harvested from the liquid medium by filtering through a filter paper, washed three times with distilled water, and dried at $60^{\circ} \mathrm{C}$ to a constant weight. The dry weight (DW) of the mycelia was determined in terms of $\mathrm{g} / 100 \mathrm{~mL}$. The dry mycelia were ground using a domestic blender, extracted 3 times with distilled water at $90^{\circ} \mathrm{C}$ for $2 \mathrm{~h}$ each, and then centrifuged at $5000 \mathrm{rpm}$ for $20 \mathrm{~min}$. The supernatants were combined and reduced pressure. The resulting concentrate was mixed with three times volume of absolute methanol, stirred vigorously and kept overnight at $4^{\circ} \mathrm{C}$. The precipitate was collected by centrifugation at 5000 rpm for $20 \mathrm{~min}$, washed twice with acetone and ether respectively, and then dried. The resulting crude $\beta$ - glucan was also estimated in terms of $\mathrm{g} / \mathrm{mL}$ (DW).

\subsection{Central Composite Design and}

\section{Response Surface Methodology}

The levels of the significant parameters and interaction effects between Medium-3 and the fungus Aspergillus niger was used for the production of $\beta$-glucan components which influence significantly the $\beta$-lucan production were analyzed and optimized by using a central composite design in response surface methodology. The experimental design was carried out by using "Stat-Ease Design-Expert" software (version 8.1, Stat-Ease Corporation, USA). The four independent factors were investigated at five different levels $(-2,-1,0,+1,+2)$. The response $\mathrm{Y}$ (yield of $\beta$-glucan) was analyzed by using a second order polynomial equation in four independent variables and the data were fitted into the equation by multiple regression procedure.

The model equation for analysis is given below Eq.

$$
\mathrm{Y}=\beta_{0}+\Sigma \beta_{\mathrm{i}} \mathrm{X}_{\mathrm{i}}+\Sigma \beta_{\mathrm{ii}} \mathrm{X}^{2}{ }_{\mathrm{i}}+\Sigma \beta_{\mathrm{ij}} \mathrm{X}_{\mathrm{i}} \mathrm{X}_{\mathrm{j}}
$$

where $Y$ is the predicted response, $X_{i}, X_{j}$ represent the independent variables which influence the response variable $\mathrm{Y}$, and $\beta_{0}, \beta_{\mathrm{i}}, \beta_{\mathrm{ii}}$, and $\beta_{\mathrm{ij}}$ represent the offset term, the ith linear coefficient, the ith quadratic coefficient and the ijth interaction coefficient, respectively. "Design-Expert"8.1 was used for regression and graphical analyses of the data obtained. Statistical analysis of the model was performed to evaluate the analysis of variance (ANOVA). The student's ttest permitted the checking of the statistical significance of the regression coefficient, and the Fischer's test determined the second-order model equation. The quality of the fit of the polynomial model equation was given by the coefficient of determination (R2). The optimum concentration of the variables were calculated from the data obtained by using the 
response surface regression procedure of the SAS statistical

\subsection{FTIR analysis of $\beta$-glucan}

$\beta$-Glucan were analyzed by FTIR-JASCO 4100 Spectrophotometer. IR spectra of the compounds were recorded for $400-4000 \mathrm{~cm}-1$ in $\mathrm{KBr}$ pellet using a FT-IR spectrophotometer.

\subsection{Antioxidant activity of polysaccharides on DPPH radical scavenging capacity}

The antioxidant activity of $\beta$-glucan were measured in terms of hydrogen donating or radical scavenging ability, using the stable radical, DPPH method [11] as modified [12]. A methanolic solution $(0.1 \mathrm{ml})$ of sample extract at various concentrations was added to $3.9 \mathrm{ml}\left(0.025 \mathrm{gL}^{-1}\right)$ of DPPH solution. The decrease in absorbance at $515 \mathrm{~nm}$ was determined continuously recorded in a spectrophotometer for 16 minutes. The decrease in the absorbance depends on the concentration of the antioxidant and the radical, the molecular structure of the antioxidant, and its kinetic behavior. The scavenging effect (decrease of absorbance at $515 \mathrm{~nm}$ ) was plotted against the time and percentage of DPPH radical scavenging ability of the sample was calculated from the absorbance value at the end of 16 min duration as follows control OD- sample OD

Percentage of DPPH activity = ---------------- X 100 control OD

\section{RESULTS}

\subsection{Isolation and identification of fungal strain}

The strains were isolated from Rhizoshere soil sample collected from the agriculture field of Palacode, Dharmapuri (Dt), Tamilnadu. Soil samples were serially diluted and were plated on Potato dextrose agar medium. The plates were incubated 72 hours at room temperature and the growth of fungal colonies was observed. The fungal colonies grown on these plates were individually sub cultured and the pure cultures of spore forming units were identified based on the colony morphology and with spore staining techniques. The individual spore forming colonies in Potato dextrose agar plates were predominantly observed to be Aspergillus sp. Among many isolates of genus Aspergillus four different colonies with different morphological characters were chosen for the studies. The organisms were identified by following standard protocols reveals that the four isolates belonging to the genus Aspergillus lies to Aspergillus niger, Aspergillus flavus, Aspergillus fumigatus, Aspergillus terreus. These organisms were further used in this study for the production of $\beta$-glucan.

\subsection{Media optimization for synthesis of $\beta$ - glucan}

The yield parameters of $\beta$-glucan the Aspergillus strains were shown in Table 1. Among the four strains tested, Aspergillus niger produced maximum of 0.5 gms $\beta$-glucans in basal medium-3 from 0.78 gms of mycelial dry weight in contrast basal medium- 4 yielded only 0.38 gms of $\beta$-glucan from 1.11 gms mycelia dry weight. Maximum $\beta$-glucan production was observed in basal medium-3 followed by basal medium2,4 .

\subsection{Central Composite Design and Response Surface Methodology}

package (Version 8.1, SAS institute inc. NC. USA)

Central Composite Design is powerful method for screening significant factor in the presence study, 14 runs were carried out to investigate the production optimization of mycelial dry weight and $\beta$-glucan using two different factors including a Carbon source (corn starch) and Nitrogen source (yeast extract). The mycelial dry weight varied greatly from $0.56 \mathrm{gms}$ to $1.28 \mathrm{gms}$ where as in $\beta$-glucan it was $0.09 \mathrm{gms}$ to 0.51 gms under different combination of media components. Response surface methodology help in evaluation of relationship between the dependent ( $\beta$-glucan yielded) variable and independent variables and predicted values of the biomass yield are shown. The accuracy of the model can be seen by the different between observed and predicted value. The co-efficient and the analysis of variance are presented in table. Fitness of the model was expected by the value of the determination co-efficient in the present $\beta$-glucan comes out to be 0.51 and 0.50 for Aspergillus niger high value of adjust co-efficient determination this adjusted 0.70 and 0.90 respectively indicate high significance of model (Fig. 2 and Fig. 3).

\subsection{Antioxidant activity by DPPH free radical scavenging assay}

The scavenging activity of $\beta$-glucan in various concentration $(10-100 \mu \mathrm{g} / \mathrm{ml})$ was determined by DPPH assay and the results are shown in Table $2 . \quad$ Increase in $\beta$-glucan concentration increases the antioxidant activity at a maximum of 78.31 percentage at $100 \mu \mathrm{g} / \mathrm{ml}$ of concentration and minimum of $1.20 \%$ at $10 \mu \mathrm{g} / \mathrm{ml}$ concentration. Similar experiments was carried out with ascorbic acid which resulted in a maximum of $51.80 \%$ radical scavenging capacity at $100 \mu \mathrm{g} / \mathrm{ml}$ concentration and a minimum of $25.30 \%$ scavenging activity at $10 \mu \mathrm{g} / \mathrm{ml}$ concentration.

\subsection{FTIR spectrum}

Figure 1 shows the FTIR spectrum of $\beta$-glucan of the Aspergillus niger isolated from basal medium -3 by Response surface methodology. The large absorption peak at $3852.5-3903.6 \mathrm{~cm}^{-1}$ was C-H stretching vibration of alkenes and asymmetrical O-H stretching absorption band at range of $3750 \mathrm{~cm}^{-1}$ was found to be $\mathrm{OH}$ stretching. Absorption peaks at 3396 and 3397 was N-H stretching of hetero aromatic compounds. C-H stretching peaks of methyl a group (Alkanes) was between $2852-2928 \mathrm{~cm}^{-1}$. The absorption band between $2345.1-2363.9 \mathrm{~cm}^{-1}$ was attributed to the carbonyl absorption bands in addition to an ammonium band. Absorption peak at $1733.8 \mathrm{~cm}^{-1}$ was $\mathrm{C}=\mathrm{O}$ stretching vibrations of the aldehyde group and $1637.0-1653.4 \mathrm{~cm}^{-1}$ was $\mathrm{NH}$ bending vibration to the amide group. The band at $1559.4 \mathrm{~cm}^{-}$ ${ }^{1}$ was $\mathrm{N}=\mathrm{O}$ absorption bands of aliphatic nitroso compounds. The band at $1419.1 \mathrm{~cm}^{-1}$ was attributed to the $\mathrm{CH}$ bending vibrations to the alkenes group. Absorption peak of cyclohexane was found nearby $1457.5 \mathrm{~cm}^{-1}$ wavelength followed by symmetrical $\mathrm{C}-\mathrm{H}$ bending vibration to the alkynes at the peak $1375.5 \mathrm{~cm}^{-1}$. Absorption peak for 1phenyl ethanol belonging to the secondary alcoholic group was observed at $1075.7-1078.9 \mathrm{~cm}^{-1}$ and peaks for phosphorus organic compounds were observed at $1164.7 \mathrm{~cm}^{-1}$. The band at $668.6-669.3 \mathrm{~cm}^{-1}$ was $\mathrm{C}-\mathrm{H}$ bending vibration to the alkynes group. 
Table 1. Yield parameter of dry weight and $\beta$-glucan by lower fungi

\begin{tabular}{|l|c|c|c|c|c|c|c|c|}
\hline \multirow{2}{*}{ Medium } & \multicolumn{2}{|c|}{ Aspergillus niger } & \multicolumn{2}{c|}{ Aspergillus flavus } & \multicolumn{2}{c|}{ Aspergillus fumigatus } & \multicolumn{2}{c|}{ Aspergillus terreus } \\
\cline { 2 - 9 } & $\begin{array}{c}\text { Dry weight } \\
\text { in grams }\end{array}$ & $\begin{array}{c}\boldsymbol{\beta} \text {-glucan } \\
\text { in grams }\end{array}$ & $\begin{array}{c}\text { Dry weight } \\
\text { in grams }\end{array}$ & $\begin{array}{c}\boldsymbol{\beta} \text {-glucan } \\
\text { in grams }\end{array}$ & $\begin{array}{c}\text { Dry weight } \\
\text { in grams }\end{array}$ & $\begin{array}{c}\boldsymbol{\beta} \text {-glucan } \\
\text { in grams }\end{array}$ & $\begin{array}{c}\text { Dry weight } \\
\text { in grams }\end{array}$ & $\begin{array}{c}\boldsymbol{\beta} \text {-glucan } \\
\text { in grams }\end{array}$ \\
\hline Seed medium & 0.73 & 0.10 & 0.60 & 0.21 & 0.38 & 0.21 & 0.70 & 0.21 \\
\hline Basal medium-1 & 0.92 & 0.09 & 0.72 & 0.09 & 0.28 & 0.17 & 0.52 & 0.24 \\
\hline Basal medium-2 & 1.6 & 0.45 & 1.5 & 0.3 & 0.43 & 0.24 & 0.66 & 0.21 \\
\hline Basal medium-3 & 0.78 & 0.5 & 0.89 & 0.27 & 0.40 & 0.15 & 0.49 & 0.32 \\
\hline Basal medium-4 & 1.71 & 0.38 & 0.87 & 0.31 & 0.31 & 0.03 & 0.81 & 0.12 \\
\hline Czapek Dox broth & 0.57 & 0.09 & 0.57 & 0.10 & 0.15 & 0.07 & 0.40 & 0.09 \\
\hline MOPT broth & 0.53 & 0.12 & 1.27 & 0.11 & 0.35 & 0.09 & 0.30 & 0.08 \\
\hline Fungal complete medium & 0.23 & 0.04 & 0.22 & 0.08 & 0.07 & 0.04 & 0.31 & 0.06 \\
\hline
\end{tabular}

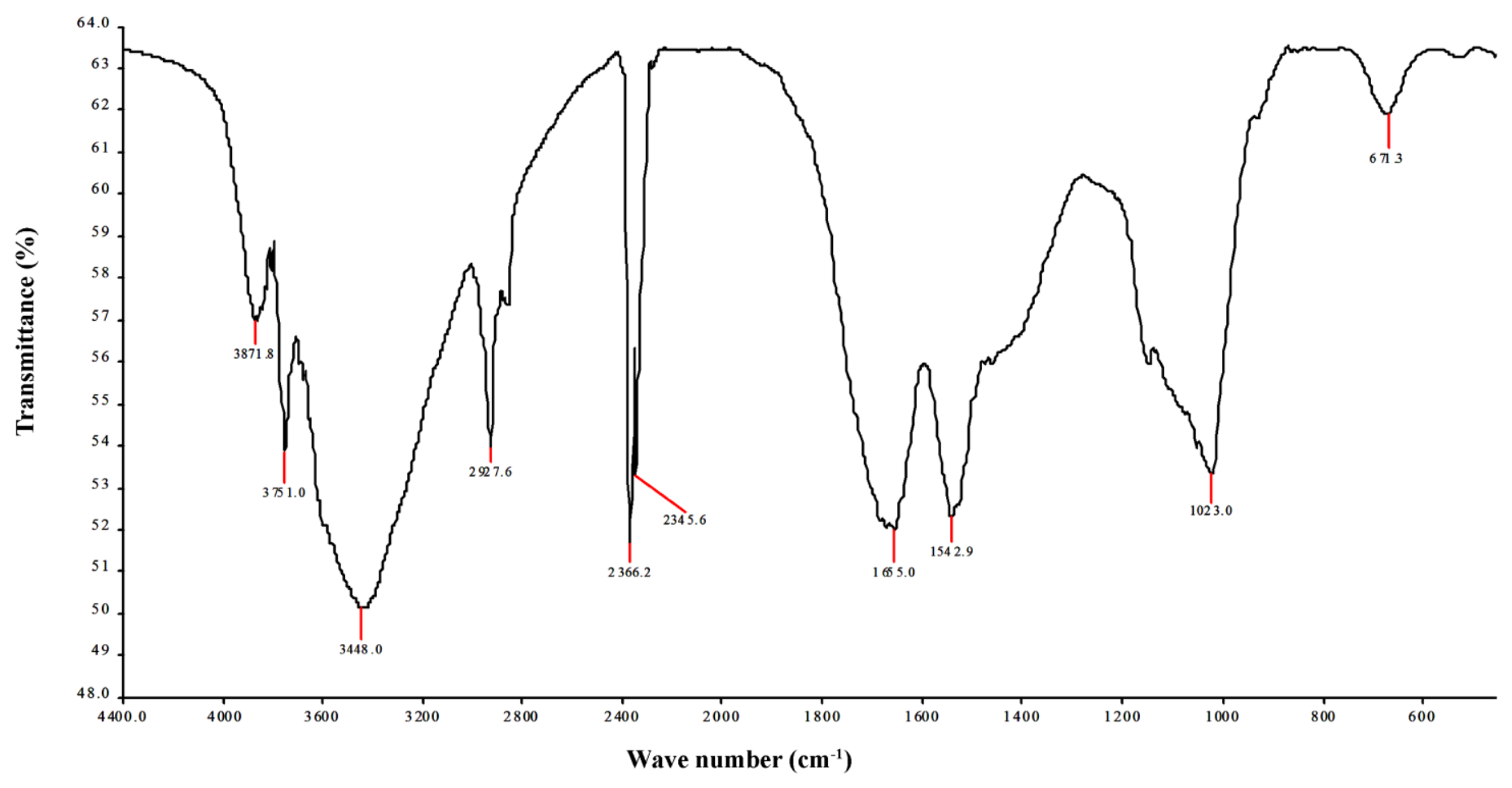

Fig. 1. Infra Red Spectrum of $\beta$-Glucan isolated from Aspergillus niger

Table 2. 1,1-Diphenyl-2-picryl hydrazyl radical scavenging capacity of $\beta$-glucan of Aspergillus niger at different concentrations

\begin{tabular}{|l|c|c|}
\hline $\begin{array}{l}\text { Concentration } \\
(\boldsymbol{\mu g} / \mathbf{m l})\end{array}$ & $\begin{array}{c}\text { DPPH Radical } \\
\text { Scavenging } \\
\text { Activity of } \boldsymbol{\beta} \text {-glucan } \\
(\boldsymbol{\%})\end{array}$ & $\begin{array}{c}\text { DPPH Radical } \\
\text { Scavenging } \\
\text { Activity of } \\
\text { Ascorbic acid }(\boldsymbol{\%})\end{array}$ \\
\hline $\mathbf{1 0}$ & 1.20 & 25.30 \\
\hline $\mathbf{2 0}$ & 3.61 & 27.71 \\
\hline $\mathbf{3 0}$ & 8.43 & 28.91 \\
\hline $\mathbf{4 0}$ & 15.66 & 31.32 \\
\hline $\mathbf{5 0}$ & 22.89 & 32.53 \\
\hline $\mathbf{6 0}$ & 27.71 & 37.34 \\
\hline $\mathbf{7 0}$ & 37.34 & 40.96 \\
\hline $\mathbf{8 0}$ & 39.63 & 43.37 \\
\hline $\mathbf{9 0}$ & 50.60 & 49.39 \\
\hline $\mathbf{1 0 0}$ & 78.31 & 51.80 \\
\hline
\end{tabular}


Design-Expert $(8)$ Software Factor Coding: Actual Dry Weight

- Design points above predic

1.28

0.56

X1 $=$ A: Corn Starch $\mathrm{X} 2=\mathrm{B}$ : Yeast Extract

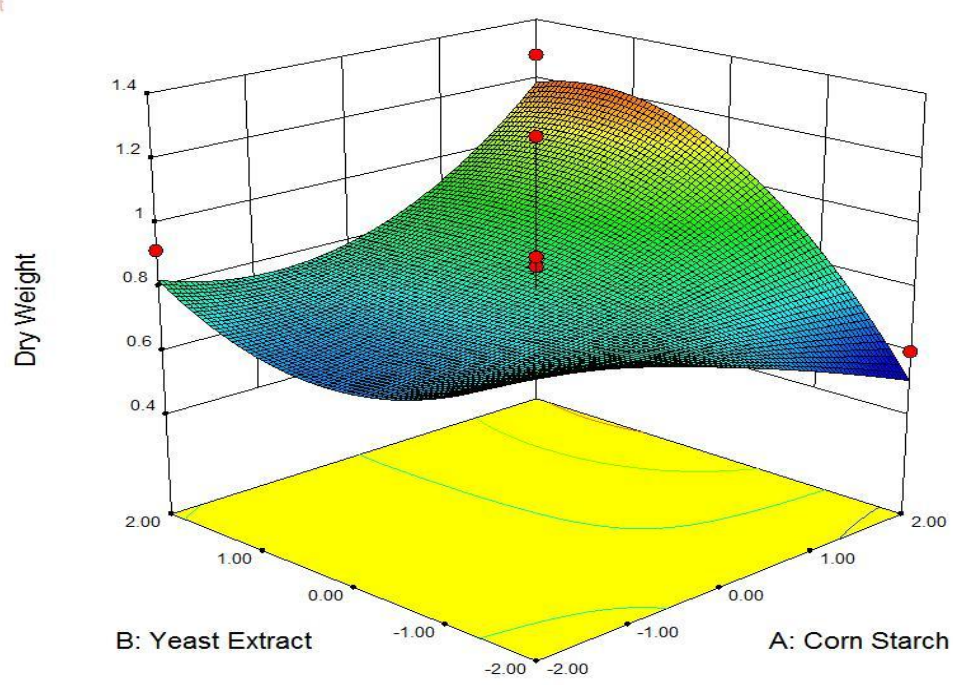

Fig. 2. Dry Weight Model Graph of Aspergillus niger in Basal M

Design-Expert 8 Software Factor Coding: Actual Beta Glucan

predic 1.2

0.09

$\times 1=A:$ Corn Starch $\times 2=$ B: Yeast Extrac

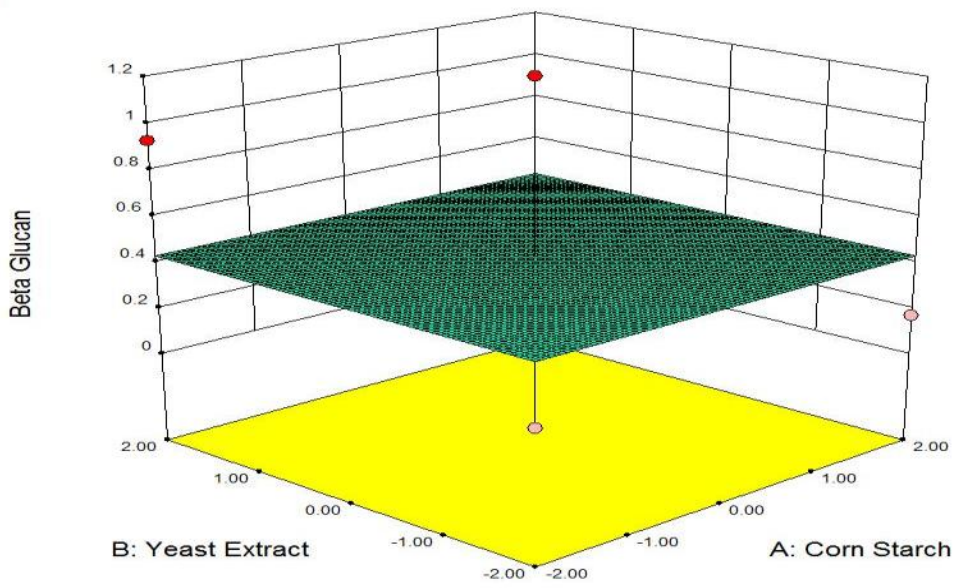

Fig.3. $\beta$-Glucan Model Graph of Aspergillus niger in Basal Media 3 
Table 3. Response surface methodology yield of $\beta$-glucan by Aspergillus niger

\begin{tabular}{|c|c|c|c|c|c|c|}
\hline RUN & $\begin{array}{c}\text { FACTOR-1 } \\
\text { (CORN } \\
\text { STARCH) }\end{array}$ & $\begin{array}{c}\text { FACTOR-2 } \\
\text { (YEAST } \\
\text { EXTRACT) }\end{array}$ & $\begin{array}{c}\text { DRY } \\
\text { WEIGHT } \\
\text { IN } \\
\text { GRAMS }\end{array}$ & $\begin{array}{c}\beta \text {-GLUCAN } \\
\text { WEIGHT IN } \\
\text { GRAMS }\end{array}$ & $\begin{array}{c}\text { pH LEVEL } \\
\text { BEFORE } \\
\text { INCUBATION }\end{array}$ & $\begin{array}{c}\text { pH LEVEL } \\
\text { AFTER } \\
\text { INCUBATION }\end{array}$ \\
\hline 1 & 0 & -2.83 & 0.60 & 0.40 & 6.5 & 6.5 \\
\hline 2 & 0.00 & 0.00 & 1.27 & 0.17 & 6.5 & 6.5 \\
\hline 3 & 2.83 & 0.00 & 1.2 & 0.50 & 6.5 & 6.5 \\
\hline 4 & -2.00 & -2.00 & 1.0 & 0.17 & 6.5 & 6.5 \\
\hline 5 & 0.00 & 0.00 & 0.59 & 0.09 & 6.5 & 6.5 \\
\hline 6 & 0.00 & 0.00 & 0.60 & 0.09 & 6.5 & 6.5 \\
\hline 7 & 0.00 & 0.00 & 0.87 & 0.32 & 6.5 & 6.5 \\
\hline 8 & 2.00 & -2.00 & 0.60 & 0.17 & 6.5 & 6.5 \\
\hline 9 & 0.00 & 0.00 & 0.56 & 0.19 & 6.5 & 6.5 \\
\hline 10 & -2.00 & 2.00 & 0.92 & 0.50 & 6.5 & 6.6 \\
\hline 11 & 0.00 & 0.00 & 0.90 & 0.48 & 6.5 & 6.5 \\
\hline 12 & 2.00 & 2.00 & 1.28 & 0.27 & 6.5 & 6.5 \\
\hline 13 & -2.83 & 0.00 & 0.57 & 0.15 & 6.5 & 6.5 \\
\hline 14 & 0.00 & 2.83 & 0.70 & 0.51 & 6.5 & 6.5 \\
\hline
\end{tabular}

\section{CONCLUSION}

RSM was used to estimate and optimize the polysaccharides production. All the independent variables, quadratic of all the independent variables had highly significant effects on the response values $(p<0.03)$. The optimal medium for $\beta$-glucan production was obtained through a central composite design in response surface methodology as follows Carbon source (corn starch $4.5 \mathrm{gm} / \mathrm{l}$ ) and nitrogen source (yeast extract 0.4 $\mathrm{gm} / \mathrm{l})$. Under these conditions, the experimental yield of polysaccharides was $0.51 \mathrm{gms}$ in the factor with preliminary media optimization experiments in basal medium-3 which was close with the predicted yield value (Table 3 ). It was also demonstrated that the administration of $\beta$-glucan could increase the antioxidant activity.

\section{REFERENCES}

[1] G.D. Ross, V. Vetvicka, J. Yan, Y. Xia, J. Vetvicková, Therapeutic intervention with complement and b-glucan in cancer, Immunopharmacology 42 (1999) 61-74

[2] K.Y. Lee, M.H. Lee, I.Y. Chang, S.P. Yoon, D.Y. Lim, Y.J. Jeon, Macrophage activation by polysaccharide fraction isolated from Salicornia herbacea, $J$. Ethnopharmacol. 103 (2006) 372-378

[3] Z. Wang, D. Luo, Antioxidant activities of different fractions of polysaccharide purified from Gynostemma pentaphyllum Makino, Carbohydr. Polym. 68 (2007) 5458.

[4] M.K. Kim, I.Y. Lee, J.H. Ko, Y.H. Rhee, Y.H. Park, Higher intracellular levels of uridine monophosphate under nitrogen-limited conditions enhance the metabolic flux of curdlan synthesis in Agrobacterium species, Biotechnol. Bioeng. 62 (1999) 317-323.

[5] P.C.K. Cheung. The hypocholesterolemic effect of extracellular polysaccharidefrom the submerged fermentation of mushroom. Nutri. Res. 16 (1996) 1953 1957.

[6] S.W. Kim, H.J. Hwang, C.P. Xu, Y.S. Na, S.K. Song, J.W. Yun, Influence of nutritional conditions on mycelial growth and exopolysaccharide production in Paecilomyces sinclairii, Lett. Appl. Microbiol. 34 (2002) 389-393.

[7] J.H. Xiao, D.X. Chen, W.H. Wan, X.J. Hu, Y. Qi, Z.Q. Liang, Enhanced simultaneous the production of mycelia and intracellular polysaccharide in submerged cultivation of Cordyceps jiangxiensis using desirability functions, Process Biochem. 41 (2006) 1887-1893.

[8] V.K. Lowry, M.B. Farnell, P.J. Ferro, C.L. Swaggerty, A. Bahl, M.H. Kogut. Purified $\beta$-glucan as an abiotic feed additive up-regulates the innate immune response in 
immature chickens against Salmonella enterica serovar Enteritidis. Int. J. Food Microbiology. 98 (2005) 309318.

[9] J.J. Volman, J.D. Ramakers, J. Plat. Dietary modulation of immune function by $\beta$-glucans. Physiol. Behavior 94 (2008) 276-284

[10] Jun Liu, Jianguang Luo, Hong Ye, Yi Sun, Zhaoxin Lu, Xiaoxiong Zeng. Production, characterization and antioxidant activities invitro of exopolysaccharides from endophytic bacterium Paenibacillus polymyxa EJS-3. Carbohydrate Polymers, 78 (2009) 275-281.

[11] W. Brand Williams, M.E. Cuvelier, C. Berset. Use of a free radical method to evaluate antioxidant activity. Lebensm. Wiss. Technol. 28 (1995) 25-30.

[12] C. Sanchez Moreno, J.A. Larrauri, F.A. Saura Calixto. A procedure to measure the antiradical efficiency of polyphenols. J. Sci. Food Agric. 76 (1998) 270-276. 